Revista Água Viva

ISSN 1678-7471

\title{
O ESPAÇO HIPERTEXTUAL E O TERCEIRO PICTURAL EM S. SEBASTIÃO, DE JOAO MIGUEL FERNANDES JORGE
}

\section{THE HYPERTEXTUAL SPACE AND THE PICTURAL THIRD IN S. SEBASTIÃO, BY JOÃO MIGUEL FERNANDES JORGE}

Lucca de Resende Nogueira Tartaglia ${ }^{1}$

Recebido em: 10 mai. 2019

Aceito em: 19 jul. 2019

DOI 10.26512/aguaviva.v4i2.24649

RESUMO: A partir da análise do poema S. Sebastião, de João Miguel Fernandes Jorge, publicado em Museu das janelas verdes, e de uma rápida passagem pelo quadro homónimo de Clemente Sánchez, este ensaio tem por objetivo refletir acerca do terceiro pictural (the pictorial third), teorizado por Liliane Louvel, e sobre o surgimento de um espaço hipertextual durante o evento de leitura (reading event). Para tanto, recorreremos a alguns apontamentos de Claus Clüver, destacados em Inter textus / inter artes / inter media, de Roland Barthes, na obra $S / Z$, e de outros autores que, direta ou indiretamente, colaborem para as discussões. Além disso, faremos uso do Diccionario histórico de los más ilustres profesores de las bellas artes en España, de Juan Agustin Cean Bermudéz, para resgatar, na medida do possível, a figura de Sanchéz.

Palavras-chave: João Miguel Fernandes Jorge; São Sebastião; Terceiro pictural.

\begin{abstract}
Through the analysis of the poem S. Sebastião, by João Miguel Fernandes Jorge, published in the Museu das janelas verdes, and a quick passage through the homonymous painting by Clemente Sánchez, this essay aims to reflect on the pictorial third, theorized by Liliane Louvel, and on the emergence of a hypertextual space during the reading event. To do so, we will use some notes by Claus Clüver, Roland Barthes and other authors who, directly or indirectly, contribute to the discussions. In addition, we will make use of the Diccionario histórico de los más ilustres profesores de las bellas artes en España, by Juan Agustin Cean Bermudéz, in order to rescue, as far as possible, the figure of Sanchéz.
\end{abstract}

Keywords: João Miguel Fernandes Jorge; São Sebastião; Pictorial Third.

\footnotetext{
${ }^{1}$ Doutorando em Letras Vernáculas, Literaturas Portuguesa e Africanas, na Universidade Federal do Rio de Janeiro (UFRJ) e investigador, pelo Programa de Doutorado Sanduíche no Exterior (PDSE), na Faculdade de Letras da Universidade do Porto. E-mail: luccatartaglia@gmail.com
} 
Ao tratar sobre um "objeto paradoxal", ou, ainda, segundo a autora, "um objeto virtualmente impossível" - a referência e/ou descrição de uma imagem, apesar de sua irredutibilidade, dentro de obras literárias -, Liliane Louvel, em A reading event The Pictorial Third, argumenta que "o dispositivo palavra/imagem desencadeia um 'evento de leitura', que provoca um fenômeno de 'dupla exposição' e cria uma 'dupla ficção'. Eventualmente, origina o 'terceiro pictural' [ou terceiro pictórico] como a consequência fenomenológica do evento de leitura"2 (LOUVEL, 2016, s. p.). Esse "terceiro pictural", segundo a autora, não é nem uma palavra (ou um conjunto de palavras) nem uma imagem, mas algo que, surgindo entre as duas coisas, se configura como uma possibilidade outra, híbrida, multifacetada e cambiável. Ainda de acordo com Louvel:

The "pictorial third" is a relation [...], it is a dynamic activity, that of a picturing reading, of a read picture. The pictorial impetus triggers the pictorial third which finds its locus in the iconotext when it arises in the reader's mind on his inner screen, on his camera obscura (LOUVEL, 2016, s.p.).

Essa camera obscura, essa "tela interior", sobre a qual emerge, numa projeção, a partir do evento de leitura, o terceiro pictural, é um espaço de trânsito, um locus hipertextual, abstrato e dinâmico, que evoca, enquanto "in-between text and image 'something' arises from the lines still veiled and hazy" (LOUVEL, 2016, s.p.), uma gama de outras imagens que, de uma maneira ou de outra, pelos mais variados motivos, se vinculam a essa imagem híbrida "floating in the reader's mind in the same way as Descartes's images in the air" (LOUVEL, 2016, s.p.).

Quando utilizamos hipertextual ${ }^{3}$ para caracterizar esse espaço dinâmico de múltiplas referências que serve de "base" ou "fundo", circundando e, de certa forma, atravessando o terceiro pictural, vale ressaltar que nos aproximamos menos da concepção de Gérard

\footnotetext{
2 "I will argue that the word/image device triggers a "reading event", that it provokes a phenomenon of "double exposure" and creates a "double fiction". It eventually gives rise to the "pictorial third" as the phenomenological consequence of the reading event". (tradução própria).

${ }^{3}$ Vale ainda destacar que utilizamos "texto", no âmbito deste trabalho, sob uma perspectiva semiótica e, portanto, mais "ampla". A respeito dessa "ampliação" do sentido, Claus Clüver, em seu artigo "Inter textus / inter artes / inter media", publicado em 2006 na revista Aletria, salienta: "Quero aqui apenas indicar que, sobretudo entre semioticistas, uma obra de arte é entendida como uma estrutura sígnica geralmente complexa -, o que faz com que tais objetos sejam denominados 'textos', independente do sistema sígnico a que pertençam. Portanto, um balé, um soneto, um desenho, uma sonata, um filme e uma catedral, todos figuram como 'textos' que se 'lêem'; o mesmo se pode dizer de selos postais, uma procissão litúrgica e uma propaganda na televisão”. (CLÜVER, 2006, p. 15)
} 
Genette $^{4}$, em Palimpsestos. La literatura em segundo grado, do que da posição de Roland Barthes, em $S / Z$, ao antecipar, de certa forma, com o "texto ideal", o que viria a ser, posteriormente, o hiperlink no ciberespaço. Em Interpretation, ainda no princípio da obra, Barthes aponta:

In this ideal text, the networks are many and interact, without anyone of them being able to surpass the rest; this text is a galaxy of signifiers, not a structure of signifieds; it has no beginning; it is reversible; we gain access to it by several entrances, none of which can be authoritatively declared to be the main one; the codes it mobilizes extend as far as the eye can reach, they are indeterminable [...]; the systems of meaning can take over this absolutely plural text, but their number is never closed, based as it is on the infinity of language (BARTHES, 2002, p. 6).

A ideia de abertura, a imagem de uma "galáxia de significantes", de relações "constelares" - ou seja, de ligações que escapam ao padrão linear e sequencial comumente utilizado - corroboram, cumulativamente, para compreendermos a natureza desse "espaço" a partir do qual o pictorial third desponta, esse locus que apresenta muitas entradas sem que nenhuma delas seja considerada a principal, tendo como catalisador a memória e a imaginação.

A fim de exemplificarmos, tanto quanto possível, na breve discussão do presente ensaio, como se dá o processo de entrecruzamento das referências nessa "tela interna", recorreremos ao poema S. Sebastião, de João Miguel Fernandes Jorge, publicado em 2002, no Museu das janelas verdes.

Os poemas que compõem o livro de João Miguel Fernandes Jorge não são, necessariamente, ecfrásticos, no sentido mais estrito do termo, porque não se limitam à descrição das imagens às quais se referem, mas, ainda assim, evocam o processo ecfrástico, uma vez que, para além das indicações deixadas pelo poeta ao fim de cada poema (com nome do pintor e data da pintura em questão), garantindo um diálogo entre as obras, os versos estabelecem uma clara relação entre a imagem verbalmente construída e as dos quadros.

A nota que acompanha o poema S. Sebastião aponta para Clemente Sánchez, um pintor espanhol do século XVII, pouco conhecido atualmente, mas mencionado, em 1800, no

\footnotetext{
${ }^{4}$ Para Genette (2010, p. 22), "todo texto derivado de um texto anterior por transformação simples (diremos daqui para frente simplesmente transformação) ou por transformação indireta: diremos imitação" é um hipertexto.
} 
Diccionario histórico de los más ilustres profesores de las bellas artes en España ${ }^{5}$ (tomo IV), de Céan Bermudéz, e para um quadro de Sánchez feito durante o primeiro quartel daquele

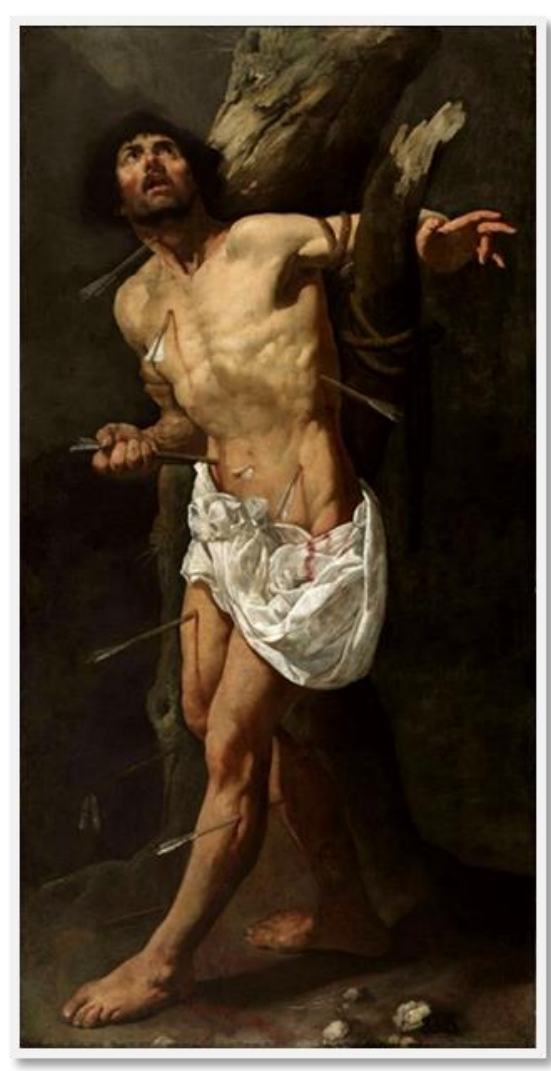

Fig. 1 - São Sebastião | Séc. XVII

Fonte: https://bit.ly/2H9ecSN. século (fig. 1) ${ }^{6}$.

A iconografia de São Sebastião - e, mais especificamente, o martírio como tema - sofreu profundas alterações durante o Renascimento, uma vez que a exposição do corpo humano alvejado favorecia o trabalho com aspectos anatómicos e destacava a beleza do corpo desnudo. A imagem que se encontra na igreja de San Pietro in Vincoli (ou Basílica de São Pedro acorrentado) carrega ainda uma das formas de representação do santo que, com o passar dos séculos, se perdeu, a de um homem, de cabelos grisalhos e barbas brancas, coberto por uma vestimenta que, possivelmente, remetia à posição de Sebastião enquanto membro da guarda imperial.

O poema de João Miguel Fernandes Jorge, ao dialogar com a obra de Sánchez, convoca não apenas a figura representada no quadro, mas também elementos da biografia do santo e do próprio pintor, fazendo com que,

para além do fenômeno produzido pelo evento de leitura e da imagem híbrida que surge a partir da dupla exposição mencionada por Louvel, várias outras conexões e referências transitem pelo locus hipertextual, revelando, perante o reader's inner eye, o mind's eye, suas inúmeras possibilidades. Para melhor evidenciar como se dá, nos versos de Jorge, esses processos, recorramos ao poema:

\section{S. SEBASTIÃO}

\footnotetext{
${ }^{5}$ No Diccionario de Barmudéz, encontramos o seguinte verbete: "Sanchez (Clemente) pintor de mérito y de buen tono en el colorido, con regular correccion en el dibuxo. Residia en Vailadolid por los años de 1620, donde pintó los quadros de los ángulos del claustro de los dominicos de Aranda de Duero, que representan los desposorios y la visitacion de nuestra Señora, la virgen del Rosario y santa María Magdalena. Pintó tambien en un retablito, colocado en la sacristía del mismo convento, á S. Juan Bautista y Santiago, á Jesus y María debaxo, y dos historias sagradas á los lados”. (BERMUDÉZ, 1800, p. 323).

${ }^{6} \mathrm{O}$ quadro de Clemente Sánchez está em Lisboa, Portugal, no Museu nacional de arte antiga. As imagens reproduzidas no presente trabalho, editadas e recortadas digitalmente, fazem parte do artigo Visiting Lisbon's Museu Nacional de Arte Antiga, do site Forgotten Masters.
} 
Para pintares Sebastião ferido, as suas próprias feridas toma uma parte de cinábrio puro e aplica a cor de fundo onde queiras ver o sangue.

Vai com uma porção de laca, em boa temperatura, marca as sombras sobre o corpo, sobre o sangue desenha gotículas, incisões, feridas sobre a mais clara carnação.

Trouxe o pintor o mais acre soldado que encontrou nas ruas de Valladolid e não deu musculatura ao feminil archeiro que dançou sobre o fogo sob o olhar de paixão, sob o desejo de Cesar. Sob o ardor da vida invoca Sebastiao a nova crença preso ao nodoso e velho loureiro, dizem, do jardim de Apolo.

As setas começam a ferir, trespassam o corpo e as mãos de terra levantam o peso desse ferro que sulca a came. Morrem os deuses antigos o vulto amado desliza sob a coluna da arvore de Apolo, as dançarinas délficas estão presentes e os grossos pés do modelo - homem do campo como não foi jamais qualquer imperial romano archeiro

esses seus pés esmagam tênues aromas, folhas de loureiro. Deu-lhe depois alguma moeda que numa taberna de soturna estrada pelo fim dos ventos altos de Castela as mãos de areia levaram esbotenada tijela aos lábios devagar saboreia devagar bebeu o escuro vinho a tênue espuma e a dura lágrima

de quem toda a vida foi martírio, encenando Sebastião ou o curvo, possante trabalho do fogo dos seus dias.

Para pintares Sebastiao no fim do suplício, quando ergue ao céu os olhos e ouve o vasto esplendor, o som da cítara que em formosura tocou não escolhas infindável adolescente toma uma parte de cinábrio puro cobre com ele o sofrimento do homem acre uma espécie de deus triste sempre ao lado da nossa vida. (JORGE, 2002, p. 54-55)

O uso constante do encavalgamento (enjambement) impede o leitor de fazer a pausa métrica e facilita o processo narrativo, criando um efeito de continuidade que minimiza o intervalo do verso e aumenta as possibilidades da descrição. O poema começa apresentando um conjunto de instruções para uma segunda pessoa, um "tu", que, para pintar "Sebastião ferido, as suas próprias feridas", terá de seguir determinados procedimentos técnicos. Se tivermos em conta que o processo de composição tende para a ecfrase, ainda que não se limite 
a ela, a imagem que surge, desde já, é anacrônica, porque cria, ao descrever um processo anterior à concepção do próprio quadro de Sánchez, uma ruptura temporal.

$\mathrm{Na}$ segunda estrofe, o tom da "narrativa" perde o caráter informativo e, de certa forma, metalinguístico (se pensarmos na descrição de um quadro que descreve como pintar o quadro descrito), e passa a relatar a escolha do modelo. Dados sobre o pintor, que escapam totalmente à imagem da pintura, surgem. Valladolid, onde, segundo o Diccionario de Barmudéz, o pintor residia em 1620, é citada e algumas coordenadas já começam a evocar

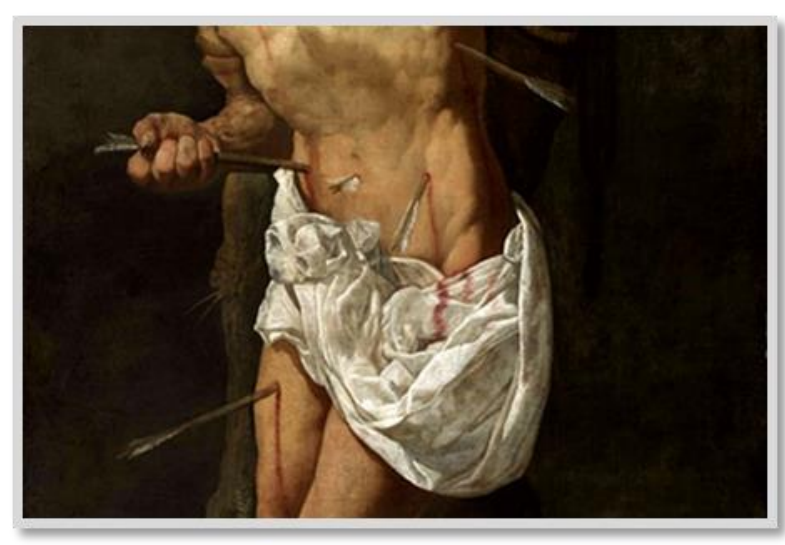
peculiaridades daquela representação específica, convocando, nessa dinâmica, uma gama de outras representações que dela se diferenciam. O "mais acre soldado" foi escolhido para servir de modelo e, ao contrário do que acontece em alguns casos como no Martírio de São Sebastião, de Gegrório Lopes, do século XVI, para o qual Jorge também dedica um poema - o "feminil arqueiro" não ganhou presença. As flechas estão lá, cravadas na carne de cor e pigmento, são o indício da presença, mas, ainda assim, apenas indício. O "desejo de Cesar" poderia ser interpretado como uma relação metonímica com o “desejo de Roma" ou do império, uma vez que foi Diocleciano, um imperador romano, que perseguiu e, por fim, condenou São Sebastião. Os tempos se entrecruzam, a vida do santo, a vida do artista, do poeta, do leitor/expectador.

O "terceiro pictural" que agora ganha corpo se move sobre o fundo enriquecido de muitas imagens, de muitos textos (no sentido lato) que compõem um quadro maior. Preso ao loureiro, árvore de Apolo, mas, também, símbolo de perseguição e condenação perpétua, tendo em vista que, de acordo com a versão de Ovídio, em Metamorfoses, surge como resultado da perseguição de uma ninfa pelo filho de Zeus e Leto, Sebastião invoca a "crença nova". Além disso, Apolo é representado, com frequência, usando um arco e carregando uma aljava de flechas; S. Sebastião, como padroeiro dos arqueiros, de certa forma, o substituiria.

As "setas começam a ferir", finalmente, na terceira estrofe. Por se tratar de um "homem do campo/ como não foi jamais qualquer imperial romano archeiro" ou qualquer representação de São Sebastião, as "mãos/ de terra" (fig. 2) e os "grossos pés" (fig. 3) do modelo são postos em evidência. 
Geralmente, a figura do santo, desde as já mencionadas alterações na sua iconografia, é carregada de traços menos "acres", mais frágeis. Representações famosas na história da arte, como a de Marco Palmezzano, de El Greco, de Botticelli ou de Rubens, aproximam a estrutura física do representado mais à anatomia tipicamente junevil do que à de um soldado adulto. Na ascensão do santo, no martírio do homem, "morrem/ os deuses antigos" e os pés esmagam, sem dar por isso, "folhas de loureiro", as mesmas que, antes, adornavam a cabeça de Apolo e eram utilizadas para coroar os "generais romanos". Sobre a coroa dos antigos, um novo reino - "uma nova crença" - se levanta.

$\mathrm{Na}$ quarta estrofe, as figuras, quase quiméricas, quase indistinguíveis, se enlaçam ainda mais, pois o homem rude é o santo e, girando à volta desse constructo que não se fixa, que não é a imagem do quadro nem a do poema, orbitando essa hybris, um universo inteiro de gravuras e ícones e símbolos se move e transita livremente. Pouca certeza há sobre quem, de fato, foi à taberna.

Se os primeiros versos revelam um momento anterior à pintura, abrindo uma fissura, um furo no tempo, agora, a descrição se desvia do quadro e segue o modelo, rompendo com o pacto ficcional que a cena exige e sobrevivendo àquele instante que, suspenso na pintura, apagou o homem "acre" e inscreveu, à imagem e semelhança, a fisionomia desaparecida do santo.

Ao fim, o tom quase injuntivo é retomado no paralelismo "Para pintar Sebastião". Porém, a instrução, dessa vez, se volta para o "fim do suplício", quando o santo "ergue ao céu os olhos”. A sugestão não parece mais ser destinada a Clemente Sánchez, uma vez que sua obra está terminada, mas ao próprio leitor/expectador ou a um outro pintor que, vendo-se na tarefa de representar o martírio, tenha de escolher um modelo. Fica recomendado: "não escolhas infindável adolescente", como fez, por exemplo, Hans Memling ou Juan Carreño de Miranda, ao retratar um "santo menino", mas, seguindo o por onde foi Sánchez, "toma uma parte de cinábrio puro/ cobre com ele o sofrimento do homem acre" e compõe, pelo contraste com as demais imagens, pela proximidade aparente com o real, um Sebastião mais santo, mas mártir, porque mais homem, mais humano, "uma espécie de deus triste sempre ao lado da nossa vida".

Se a visual reading experience confere ao texto um aspecto híbrido, assegurando, através da dupla exposição, a emergência de um "terceiro pictural", desencadeia também os passos em volta desse evento fenomenológico, inaugurando o fundo sobre o qual uma imagem virtual é projetada pelos textos (verbal e não-verbal). No caso do poema de João 
Miguel Fernandes Jorge, toda uma tradição iconográfica do martírio de São Sebastião é convocada, assim como aspectos ligados ao antigo e ao moderno, à vida do pintor, ao próprio ato de pintar e de representar.

Esse lugar intermédio, a partir do qual surge a imagem cinemática de um Sánchez em diferentes momentos da composição do quadro - preparando a tela, escolhendo o modelo, fixando a imagem, pagando pelo serviço - e de instantes posteriores ao fim da pintura, comporta e põe em movimento todos esses fragmentos que, reunidos pelo liame da memória, constituem, na imaginação, a imensa tela interior sobre a qual o filme, composto a muitas mãos, é projetado.

\section{REFERÊNCIAS}

AZEVEDO, Carlos A. Moreira et al. O mártir: corpo ferido na árvore. Santa Maria da Feira: Câmara Municipal de Santa Maria da Feira, 2005.

BARTHES, Roland. S/Z. Tradução de Richard Miller. New York: Hill and Wang, 2002.

BERMUDÉZ, Juan Agustin Cean. Diccionario histórico de los más ilustres profesores de las bellas artes en España. Vol. IV. Madrid: La real academia de S. Fernando, 1800.

CLÜVER, Claus. Inter textus / inter artes / inter media. Aletria, jul.-dez. 2016. Disponível em: http://www.letras.ufmg.br/poslit. Acesso em: 13 nov. 2018.

GIORGI, Rosa. Dizionari dell'Arte: Santi. Milão: Electa, 2003.

JORGE, Joao Miguel Fernandes. Museu das Janelas Verdes. Lisboa: Relógio D' Agua, 2002.

LOUVEL, Liliane. A reading event "The Pictorial Third". Sillages critiques, n. 21, dez. 2016. Disponível em: http://journals.openedition.org/sillagescritiques/5015. Acesso em: 03 jan. 2019.

GENETTE, Gérard. Palimpsestos: a literatura de segunda mão. Tradução de Cibele Braga, Erika Viviane Costa Vieira, Luciene Guimarães, Maria Antônia Ramos Coutinho, Mariana Mendes Arruda e Miriam Vieira. Belo Horizonte: Edições Viva Voz, 2010. 